\title{
MicroRNAs in the context of human diseases
}

\author{
E Sonkoly \\ From 5th European Workshop on Immune-Mediated Inflammatory Diseases \\ Sitges-Barcelona, Spain. 1-3 December 2010
}

The discovery of microRNAs is one of the major scientific breakthroughs in recent years and has revolutionized the way we look at gene regulation. MicroRNAs are small non-coding RNAs that regulate the expression of protein-coding genes via posttranscriptional suppression. Each microRNA can regulate dozens to hundreds of genes, making their regulatory potential enormous. MicroRNAs regulate basic biological processes and have been implicated in the development of the immune system as well as in immune responses.

In line with their essential role in physiological processes, deregulation of microRNAs has been linked to human diseases. MicroRNAs are frequently deregulated in cancers. In the past few years, dozens of microRNAs were identified, which act as tumor suppressors or oncogens and regulate carcinogenesis, tumor progression and metastasis. Recently, deregulation of microRNAs has been shown in chronic inflammatory and immunemediated diseases such as psoriasis, atopic dermatitis, rheumatoid arthritis and systemic lupus erythematosus. However, we are still at the beginning in understanding their roles in the regulation of inflammatory pathways and the pathogenesis of inflammatory diseases.

Since microRNA levels can be modulated by introducing microRNA mimics and inhibitors to the cells, we predict that overexpression or suppression of microRNA levels may become a novel therapeutic approach in the treatment of cancer and inflammatory diseases in the future.

Published: 25 November 2010

Dermatology and Venerology Unit, Dept. of Medicine, Karolinska Institutet, Stockholm, Sweden
doi:10.1186/1479-5876-8-S1-18

Cite this article as: Sonkoly: MicroRNAs in the context of human diseases. Journal of Translational Medicine 2010 8(Suppl 1):18.
Submit your next manuscript to BioMed Central and take full advantage of:

- Convenient online submission

- Thorough peer review

- No space constraints or color figure charges

- Immediate publication on acceptance

- Inclusion in PubMed, CAS, Scopus and Google Scholar

- Research which is freely available for redistribution 